\title{
Can enriching emotional intelligence improve medical students' proactivity and adaptability during OB/GYN clerkships?
}

\author{
Stephanie H. Guseh, Xiaodong P. Chen, Natasha R. Johnson
}

Department of Obstetrics, Gynecology and Reproductive Biology, Harvard Medical School, Brigham and Women's Hospital, Boston, Massachusetts, USA

Correspondence: Natasha R. Johnson, Department of Obstetrics, Gynecology and Reproductive Biology, Harvard Medical School, Brigham and Women’s Hospital, Boston, Massachusetts, USA. Email: nrjohnson@partners.org

Accepted: November 27, 2015

\begin{abstract}
Objective: The purpose of this pilot study was to examine our hypothesis that enriching workplace emotional intelligence through resident coaches could improve third-year medical students' adaptability and proactivity on the Obstetrics and Gynecology clerkship.

Methods: An observational pilot study was conducted in a teaching hospital. Fourteen 3rd year medical students from two cohorts of clerkships were randomly divided into two groups, and equally assigned to trained resident coaches and untrained resident coaches. Data was collected through onsite naturalistic observation of students' adaptability and proactivity in clinical settings using a checklist with a 4point Likert scale ( $1=$ poor to $4=$ excellent). Wilcoxon ranksum test was used to compare the differences between these two groups.

Results: A total of 280 data points were collected through onsite observations conducted by investigators. All $(n=14)$ students' adaptability and proactivity performance
\end{abstract}

significantly improved from an average of 3.04 to 3.45 $(\mathrm{p}=0.014)$ over 6 -week clerkship. Overall, students with trained resident coaches adapted significantly faster and were more proactive in the obstetrics and gynecology clinical setting than the students with untrained coaches (3.31 vs. $3.24, \mathrm{p}=0.019$ ).

Conclusions: Findings from our pilot study supported our hypothesis that enriching workplace emotional intelligence knowledge through resident coaches was able to help medical students adapt into obstetrics and gynecology clinical settings faster and become more proactive in learning. Clerkship programs can incorporate the concept of a resident coach in their curriculum to help bridge medical students into clinical settings and to help them engage in self-directed learning throughout the rotation.

Keywords: Emotional intelligence, obstetrics and gynecology, resident coach, clerkship

\section{Introduction}

Emotional Intelligence (EI), which usually includes adaptability and proactivity as key components, is the ability to identify, process, control, and manage the emotions of oneself and others. ${ }^{1}$ Many studies have shown that measurements of EI tended to correlate with academic and professional success - including in the medical setting and workplace. ${ }^{2}$ There is increasing interest in defining EI within the medical sphere as it is naturally related to the new Accreditation Council for Graduate Medical Education (ACGME) core competencies of professionalism, patient care, and interpersonal and communication skills. ${ }^{3}$ Some authors have suggested that an assessment of EI should be included as part of the residency application process. ${ }^{4}$ Although many studies have proposed incorporating EI into the medical curriculum, few have described specific methods of enhancing the EI of medical students during their third year clerkships..$^{5-6}$

Adaptability, which refers to an ability to change oneself to adjust to occurring changes in the environment, is one component of the self-management sphere of workplace emotional intelligence (WEI) that is critical for success during medical school clerkships. ${ }^{7}$ The complex and dynamic nature of the medical environment often makes medical students feel stressed when rotating in a new 
clerkship. Clerkship students who are in distress may experience cognitive changes that affect their learning. Thus, if medical students are able to rapidly adapt to multiple different care teams as well as various clinical settings, they would be able to integrate themselves into the medical culture, become less stressed, but more active participants, and be well prepared for their learning in OB/GYN. ${ }^{8}$ In addition, a recent study showed that adaptability was one domain of EI in which resident physicians score lower than the general population - thus highlighting the need for specific training in medical school curricula. ${ }^{9}$

Proactivity, which refers to acting in advance of a future situation rather than just reacting, is another component of WEI about self-starting and being change-oriented in order to enhance personal or organizational effectiveness. ${ }^{10,11}$ Proactive behaviors in the workplace include seeking feedback, ${ }^{12-14}$ actively adapting to new environments, ${ }^{15-17}$ taking initiative in pursuing personal and organizational goals, ${ }^{18}$ and implementing ideas and solving problems. ${ }^{19}$ In medical education, proactive medical students usually do not require prompting to complete assigned tasks or require detailed instructions. Students' proactive behaviors during the clerkship, thus, are believed to have a positive influence on their learning experience.

Although many studies about WEI have been conducted in the medical environment, few of them focus on effective methods to deliver WEI knowledge to medical students during clerkships. At academic teaching hospitals, residents play a critical role in the education of medical students as they rotate through various clerkships. Residents have been identified as having a significant impact on students' ability to integrate into the medical system and adapt to specific cultural patterns within medicine..$^{20,21}$ However, as these abilities could be difficult to teach in a group format as well as students' diverse clerkship schedules, we hypothesized that utilizing resident coaches, in which residents work oneon-one with medical students directly or remotely, we could deliver WEI knowledge to students and help them adapt faster and become more proactive in the OB/GYN clinical setting during the clerkship. Therefore, we conducted this study to pilot test our hypothesis that enriching students' workplace emotional intelligence (WEI) knowledge through resident coaches could improve medical students' adaptability and proactivity on the OB/GYN clerkship.

\section{Methods}

\section{Study design}

This was an observational study conducted during the academic year 2013-2014 within the OB/GYN Medical Student Clerkship at Brigham and Women's Hospital and Integrated Residency Program at Brigham and Women's Hospital and Massachusetts General Hospital, which both are teaching hospitals affiliated with Harvard Medical School. The OB/GYN clerkships are 6 weeks (3 consecutive weeks focusing on OB and 3 consecutive weeks on GYN) in length for third-year Harvard Medical School students; residency training is 4 years for $\mathrm{OB} / \mathrm{GYN}$ residents in these institutions. The OB/GYN clerkship consists of 6 to 7 students who rotate through different clinical settings, including: labor and delivery, operating room, inpatient, gynecology oncology, and ambulatory clinics over the course of the 6 weeks.

\section{Resident coach program}

Based on prior medical student needs assessment and resident feedback, the OB/GYN clerkship leadership in conjunction with administrative OB/GYN chief residents initiated the Resident Coach Program in the academic year 2012-2013 as part of the Resident-as-Teacher (RaT) Curriculum for third-year medical students. The main goal of the Resident Coach Program is to provide students with oneon-one support and guidance from residents in person or remotely during their clerkship. Each student is assigned a second or third-year OB/GYN resident as their coach for the 6-week clerkship. The resident coaches follow a standardized job description, which consists of an initial meeting and several check-in points over the course of the 6 weeks, provide students with educational resources, and culminate with aiding in oral examination and shelf examination preparation in the final week. The resident coach is available for any other guidance or support (e.g. suturing, knot tying, patient presentation practice) requested by the student. Given the well-established successful resident coach program in our OB/GYN clerkship, it was chosen as the pilot test platform to deliver the WEI knowledge to medical students.

\section{Study participants}

All of 14 third-year clerkship students (6 female students and 8 male students) and 14 PGY2 and PGY3 resident coaches participated over the course of two 6-week clerkships in this pilot study. To decrease the potential selection bias, all participating students needed to demonstrate similar pre-clerkship academic performance. Individual $\mathrm{OB} / \mathrm{GYN}$ residents from the 2nd postgraduate year (PGY2) and the 3rd postgraduate year (PGY3) were randomly assigned as resident coaches to each 3rd medical student who participated in the OB/GYN clerkship as part of the already established Resident Coach Program described above. These resident coaches were randomly divided into two groups: resident coaches from group 1 were trained and instructed to teach students WEI, while coaches from the other group (group 2) were not. The WEI training curriculum, which included introductory of clinical environment and resources, the student's role on the working team, and a list of recommended clinical learning tasks, were provided to residents from group 1. Clerkship expectations for resident coaches (e.g. scheduled times to "check-in" during the clerkship) and instruction regarding adequate support 
for the students were also included as general training components for resident coaches in both groups.

This study received Institutional Review Board (IRB) approval from both Harvard Medical School and Brigham and Women's Hospital.

\section{Data collection and analysis}

Data was collected through onsite naturalistic observations of students' clerkship performance in different clinical settings with an evaluation checklist which was derived from validated EI literature. ${ }^{1,22-24}$ According to the taxonomy of adaptive performance, ${ }^{23}$ ten checklist rating items from 5 dimensions were developed: physically and environmental adaptability, interpersonal adaptability, cultural adaptability, dealing with uncertain work situations, and learning work tasks/technologies/procedures (Table 1).

Table 1. Workplace Emotional Intelligence (WEI) checklist items

\begin{tabular}{|c|c|c|}
\hline Category & Checklist Items & Definition \\
\hline \multirow{2}{*}{$\begin{array}{l}\text { Physically and } \\
\text { environmental } \\
\text { adaptability }\end{array}$} & Locate patient & $\begin{array}{l}\text { Able to find the patient/exam room } \\
\text { successfully without asking for help }\end{array}$ \\
\hline & Movement & $\begin{array}{l}\text { Able to adjust body movements } \\
\text { instantly based on the clinical setting } \\
\text { without reminder }\end{array}$ \\
\hline \multirow{2}{*}{$\begin{array}{l}\text { Interpersonal } \\
\text { adaptability }\end{array}$} & Self-Introduction & $\begin{array}{l}\text { Able to greet and/or self-introduce to } \\
\text { the team without reminder }\end{array}$ \\
\hline & Call Names & $\begin{array}{l}\text { Able to remember and call most team } \\
\text { members' names }\end{array}$ \\
\hline \multirow{2}{*}{$\begin{array}{l}\text { Cultural } \\
\text { adaptability }\end{array}$} & Team Structure & $\begin{array}{l}\text { Able to identify the right team member } \\
\text { to ask for appropriate support }\end{array}$ \\
\hline & Setting & $\begin{array}{l}\text { Able to demonstrate understanding of } \\
\text { the current clinical setting (e.g. } \\
\text { patient's need for privacy, schedule) }\end{array}$ \\
\hline $\begin{array}{l}\text { Dealing with } \\
\text { uncertain work } \\
\text { situations }\end{array}$ & Reaction & $\begin{array}{l}\text { Able to demonstrate understanding of } \\
\text { his/her role, join the team, and provide } \\
\text { appropriate support without residents' } \\
\text { and/or faculty's prompting }\end{array}$ \\
\hline \multirow{3}{*}{$\begin{array}{l}\text { Learning work } \\
\text { tasks, } \\
\text { technologies, } \\
\text { and proce- } \\
\text { dures }\end{array}$} & Understand Task & $\begin{array}{l}\text { Able to respond to the order quickly } \\
\text { and accurately without prompting }\end{array}$ \\
\hline & Discuss Task & $\begin{array}{l}\text { Able to identify learned knowledge for } \\
\text { the task and discuss alternatives } \\
\text { without prompting }\end{array}$ \\
\hline & Perform Task & $\begin{array}{l}\text { Able to perform and complete the task } \\
\text { successfully without asking for help }\end{array}$ \\
\hline
\end{tabular}

A 4-point Likert scale (1=poor), (4=excellent) which was derived from an existing adaptability measurement inventory with detailed rating description was applied. ${ }^{25}$ Expert validation was conducted with 2 faculty members, who had sufficient experience in clerkship students' cognitive behaviors and psychometric evaluation, to ensure the checklist items' clarity and relevance to the construct. Cognitive pretesting was then applied to collect feedback from 2 residents and 1 faculty to ensure potential participants interpreted the checklist items as they were intended.

All observations were conducted by a medical educator, non-coach residents, or faculty members. Each student was observed at least twice: once towards the midpoint of the first 3 weeks of the clerkship and once towards the midpoint of the second 3 weeks. All observers were contacted prior to the data collection. If the observer agreed to participate in the study, the checklist would be sent out. All the observers returned the checklists to the investigator within the assigned time frame (e.g. Tuesday to Thursday of the 2nd week). Data from observers was then aggregated into an excel file. Wilcoxon Signed-Rank test was used to compare the differences of students who had WEI trained coaches to those who had untrained coaches depending on the data distribution. $P$ values less than 0.05 were considered statistically significant.

\section{Results}

A total of 14 third-year medical students (6 female students and 8 male students) and 14 PGY2 and PGY3 resident coaches participated over the course of two 6-week clerkships in this pilot study. All participating students demonstrated similar pre-clerkship academic performance. Each student was randomly assigned to either a PGY 2 or PGY 3 OB/GYN resident coach according to the RaT resident coach curriculum. A total of 280 data points were collected through onsite observations.

All of the medical students' adaptability and proactivity performance significantly improved from an average of 3.04 during the first 3 weeks of the clerkships to 3.45 during the last 3 weeks of the clerkships $(\mathrm{P}=0.014)$ over two 6-week clerkships (Table 2).

Table 2. Overall Scores of Medical Students' Adaptability and Proactivity in the 6-week OB/GYN Clerkship

\begin{tabular}{|c|c|c|c|c|}
\hline Category & Checklist item & $\begin{array}{l}\text { First } 3 \\
\text { weeks }\end{array}$ & $\begin{array}{l}\text { Second } 3 \\
\text { weeks }\end{array}$ & Difference \\
\hline \multirow{2}{*}{$\begin{array}{l}\text { Physically and } \\
\text { environmental } \\
\text { adaptability }\end{array}$} & Locate patient & 3.14 & 3.69 & 0.55 \\
\hline & Movement & 3.25 & 3.63 & 0.38 \\
\hline \multirow{2}{*}{$\begin{array}{l}\text { Interpersonal } \\
\text { adaptability }\end{array}$} & $\begin{array}{l}\text { Self- } \\
\text { introduction }\end{array}$ & 3.12 & 3.63 & 0.51 \\
\hline & Call names & 3.21 & 3.23 & 0.02 \\
\hline \multirow{2}{*}{$\begin{array}{l}\text { Cultural } \\
\text { adaptability }\end{array}$} & Team structure & 3.81 & 3.75 & -0.06 \\
\hline & Setting & 2.92 & 3.39 & 0.47 \\
\hline $\begin{array}{l}\text { Dealing with } \\
\text { uncertain work } \\
\text { situations }\end{array}$ & Reaction & 2.98 & 3.52 & 0.54 \\
\hline \multirow{3}{*}{$\begin{array}{l}\text { Learning work } \\
\text { tasks, technolo- } \\
\text { gies, and proce- } \\
\text { dures }\end{array}$} & $\begin{array}{l}\text { Understand } \\
\text { task }\end{array}$ & 3.13 & 3.32 & 0.19 \\
\hline & Discuss task & 2.69 & 3.18 & 0.49 \\
\hline & Perform task & 2.82 & 3.15 & 0.33 \\
\hline \multicolumn{2}{|l|}{ Average } & 3.04 & 3.45 & $0.41^{*}$ \\
\hline
\end{tabular}

Note: During the 6-week OB/GYN clerkship, 3 consecutive weeks usually focus on $O B$ context and 3 consecutive weeks on GYN context. Overall scores calculated over 2 consecutive 6 week clerkships for students in both Group 1 and Group 2.

$p$ value $=0.014$ calculated by Wilcoxon Signed-Rank test.

Medical students demonstrated substantial improvement in dealing with uncertain work situations ( 2.98 vs. 3.52$)$ when comparing their ratings in the first 3 weeks of the clerkships to the second 3 weeks of the clerkships. Moderate-tosubstantial improvements were also observed in medical students' "physically and environmental adaptability" and "learning work tasks, technologies, and procedures" (Table 2). Overall ratings for the adaptability and proactivity in groups 1 (WEI trained) and 2 (non-WEI trained) are shown in Table 3. Across both 6-week clerkships, it is notable that 
the average performance of students in group 1 was significantly better than the students in group 2 (3.31 vs. 3.24, $\mathrm{P}=0.019$ ). Students in group 1 tended to show better adaptability and proactivity in four tasks: "locating the patient (3.54 vs. 3.33)", "movement (3.58 vs. 3.27 )", "understanding the setting ( 3.35 vs. 3.00$)$ ", and "discussing tasks ( 3.38 vs. 3.05)". Students in group 2 were more likely to be proficient at: "knowing team structures" and "performing tasks" during the 6-week clerkship periods. No substantial differences between the two groups in the following tasks were observed: "self-introduction", “calling team members' names", "reacting to uncertainty", and "understanding tasks".

Table 3. Overall scores of medical students' adaptability and proactivity in the 6-week OB/GYN clerkship between groups

\begin{tabular}{|c|c|c|c|c|}
\hline Category & $\begin{array}{l}\text { Checklist } \\
\text { item }\end{array}$ & Group 1 & Group 2 & Difference \\
\hline \multirow{2}{*}{$\begin{array}{l}\text { Physically and } \\
\text { environmental } \\
\text { adaptability }\end{array}$} & $\begin{array}{l}\text { Locate } \\
\text { patient }\end{array}$ & 3.54 & 3.33 & 0.24 \\
\hline & Movement & 3.58 & 3.27 & 0.31 \\
\hline \multirow{2}{*}{$\begin{array}{l}\text { Interpersonal } \\
\text { adaptability }\end{array}$} & $\begin{array}{l}\text { Self- } \\
\text { introduction }\end{array}$ & 3.36 & 3.36 & 0.00 \\
\hline & Call names & 3.19 & 3.25 & -0.06 \\
\hline \multirow[t]{2}{*}{ Cultural adaptability } & $\begin{array}{l}\text { Team } \\
\text { structure }\end{array}$ & 3.70 & 3.88 & -0.18 \\
\hline & Setting & 3.35 & 3.00 & 0.35 \\
\hline $\begin{array}{l}\text { Dealing with uncertain } \\
\text { work situations }\end{array}$ & Reaction & 3.27 & 3.18 & 0.09 \\
\hline \multirow{3}{*}{$\begin{array}{l}\text { Learning work tasks, } \\
\text { technologies, and } \\
\text { procedures }\end{array}$} & $\begin{array}{l}\text { Understand } \\
\text { task }\end{array}$ & 2.97 & 2.89 & 0.08 \\
\hline & $\begin{array}{l}\text { Discuss } \\
\text { task }\end{array}$ & 3.38 & 3.05 & 0.33 \\
\hline & $\begin{array}{l}\text { Perform } \\
\text { task }\end{array}$ & 2.74 & 3.23 & -0.49 \\
\hline Average & & 3.31 & 3.24 & $0.07^{*}$ \\
\hline
\end{tabular}

Note: Overall scores calculated over 2 consecutive 6 week clerkships. Scores based on WEI instrument using 4 point Likert scale; $1=$ poor to $4=$ =xcellent; Group 1Students paired with Resident Coaches trained in Workplace Emotional Intelligence (WEI), Group 2- Students paired with Resident Coaches not trained in WEI.

$p$ value $=0.019$ calculated by Wilcoxon Signed-Rank test.

\section{Discussion}

The aim of our study was to investigate whether enriching WEI knowledge through resident coaches could improve students' adaptability and proactivity on their OB/GYN clerkship. Students who were paired with trained resident coaches (Group 1) demonstrated significantly higher levels of overall adaptability and proactivity within the 6 week clerkships. Our results suggested that trained resident coaches provided a feasible platform to deliver WEI knowledge to medical students when entering a new clerkship and help students adapt faster and become proactive during the OB/GYN clerkship.

The ability to quickly adapt to a physical environment is a key aspect of effective performance. ${ }^{23} \mathrm{OB} / \mathrm{GYN}$ uniquely combines multiple clinical settings, including labor and delivery, operating room, outpatient, and inpatient, thus students face bigger challenges of adapting quickly and effectively to different clinical settings than in other core clerkships. In order to maximize their learning potential and to promote proactive self-directed learning, enriching students' WEI is essential. Our findings revealed that WEI knowledge was not only feasible to be delivered through trained resident coaches, but also able to help medical students improve their physical and environmental adaptability, such as locating patients and appropriately adjusting their movement, and thus immerse themselves into the OB/GYN culture and settings at our hospital. Results from this study also indicated that students with enriched WEI knowledge engaged in seeking novel ways to solve problems in a changing situation which was consistent with the existing literature. ${ }^{23,26}$ In addition, students with WEItrained coaches demonstrated superior performance in the categories of cultural adaptability and learning work tasks. Thus, the WEI knowledge imparted through trained resident coaches likely contributed to the students' adaptability and proactivity during the OB/GYN clerkship.

Although students in group 1 outperformed those in group 2 in a number of categories on the checklist, it is interesting that the students in group 2 received higher ratings in "identifying team structure" and "completing a task". According to the literature of situated learning, expertise development, and learning curves, ${ }^{27-29}$ a possible explanation may be that medical students with untrained resident coaches (group 2) became more proficient at independently locating helpful resources through selfdirected exploration of the environment. Without adequate WEI knowledge about our OB/GYN environment and learning context, these students would have to rely on themselves to adapt to the environment, and consequently would be expected to demonstrate somewhat delayed learning progress. They might rely more on identifying team structure in order to find appropriate support to accelerate their learning and adaption in different clinical environments. Based on the learning curve model, these students might become more efficient after they ultimately achieve a steep acceleration in learning. As a result, they might perform tasks better than their WEI-trained counterparts during the study period. This finding also leads to an important question for medical education regarding the balance of guided support versus independence for third year medical students during clerkships. Future studies are needed to explore how resident coaches and WEI knowledge might influence medical students' skills acquisition, learning development, and progressive independence during clerkships.

Our pilot study has demonstrated the possibility and practicability of using resident coaches to help medical students adapt into OB/GYN clinical settings faster and to become more proactive in clerkship learning through enriching their WEI knowledge. However, it has several limitations. As this was a single-institution pilot study and had small participant numbers, we did not expect to demonstrate significant effects and generalizability in our outcome measures. Likewise, there is an increased likeli- 
hood of false negative results of statistical data analysis as our study had limited sample size. In addition, our findings may be influenced by limited representativeness as well as social and personal bias. All medical students voluntarily participated in the study, but they may not represent a full population of 3rd year medical students. Although standardized checklists with detailed rating descriptions were used and non-coach residents were applied to data collection, the ratings might be subject to the observers' biases, influenced by students' social desirability and personalities. However, our findings were still able to test the hypothesis of our study and provided empirical pilot data for other clerkship programs to reference. Future studies with larger sample sizes and further replication of these findings in other institutions with multiple evaluators would be a beneficial next step.

\section{Conclusions}

Enriching WEI knowledge through resident coaches is a practical and effective method to improve medical students' adaptability and proactivity in learning during the OB/GYN clerkship, which is paramount to the medical education experience. Clerkship programs can easily embrace resident coaches into their clerkship curriculum to boost students' preparedness, equip them with WEI knowledge, and guide them to carry out self-directed learning throughout the clerkship rotations.

\section{Conflict of Interest}

The authors declare that they have no conflict of interest.

\section{References}

1. Salovey P, Mayer J. Emotional intelligence. Imagination Cognition and Personality. 1989;9(3):185-211.

2. Arora S, Ashrafian H, Davis R, Athanasiou T, Darzi A, Sevdalis N. Emotional intelligence in medicine: a systematic review through the context of the ACGME competencies. Med Educ. 2010; 44(8):749-64.

3. McKinley SK, Petrusa ER, Fiedeldey-Van DC, Mullen JT, Smink DS, Scott-Vernaglia SE, et al. Are there gender differences in the emotional intelligence of resident physicians? J Surg Educ. 2014;71(6):e33-40.

4. Lin DT, Kannappan A, Lau JN. The assessment of emotional intelligence among candidates interviewing for general surgery residency. J Surg Educ.2013;70(4):514-21.

5. Cherry MG, Fletcher I, O'Sullivan H, Shaw N. What impact do structured educational sessions to increase emotional intelligence have on medical students? BEME Guide No. 17. Med Teach. 2012; 34(1):11-9.

6. Taylor C, Farver C, Stoller JK. Perspective: can emotional intelligence training serve as an alternative approach to teaching professionalism to residents? Acad Med. 2011;86(12):1551-4.

7. Stoller J, Taylor C, Farver C. Emotional intelligence competencies provide a developmental curriculum for medical training. Med Teach. 2013;35(3):243-7.
8. Murdoch-Eaton D, Whittle S. Generic skills in medical education: developing the tools for successful lifelong learning. Med Educ. 2012;46(1):120-128.

9. McKinley SK, Petrusa ER, Fiedeldey-Van Dijk C, Mullen JT, Smink DS, Scott-Vernaglia SE, et al. A multi-institutional study of the emotional intelligence of resident physicians. Am J Surg. 2015; 209(1):26-33.

10. Holman D, Wall TD, Clegg CW, Sparrow P, Howard A. The new workplace: a guide to the human impact of modern working practices. Chichester (UK); John Wiley \& Sons; 2003.

11. Unsworth KL, Parker S. Proactivity and innovation: Promoting a new workforce for the new workplace. [cited 23 November 2015]; Available from: http://eprints.qut.edu.au/2949/2/2949.pdf.

12. Ashford SJ, Blatt R, VendeWalle D. Reflections on the looking glass: a review of research on feedback-seeking behavior in organizations. Journal of Management. 2003;29: 769-799.

13. Ashford SJ, Cummings LL. Feedback as an individual resource: personal strategies of creating information. Organizational Behavior and Human Performance. 1983;32:370-398.

14. Ashford SJ, Cummings LL. Proactive feedback seeking: the instrumental use of the information environment. Journal of Occupational Psychology. 1985;58:67-79.

15. Kim TY, Cable DM, Kim SP. Socialization tactics, employee proactivity, and person-organization fit. J Appl Psychol. 2005; 90(2):232-41.

16. Saks AM, Ashforth B. Proactive socialization and behavioral selfmanagement. Journal of Vocational Behavior. 1996;48:301-323.

17. Wanberg CR, Kammeyer-Mueller JD. Predictors and outcomes of proactivity in the socialization process. Journal of Applied Psychology. 2000;85:373-385.

18. Fay D, Frese M. The concept of personal initiative: an overview of validity studies. Human Performance. 2001;14:97-124.

19. Parker SK, Williams HM, Turner N. Modeling the antecedents of proactive behavior at work. Journal of Applied Psychology. 2006;9:636-652. 20. Karani R, Fromme HB, Cayea D, Muller D, Schwartz A, Harris IB. How medical students learn from residents in the workplace: a qualitative study. Acad Med. 2014;89(3):490-6.

21. Yu TC, Lemanu DP, Henning M, Maccormick AD, Hawken SJ, Hill AG. General surgical interns contributing to the clerkship learning environment of medical students. Med Teach. 2013; 35(8):639-47.

22. Austin EJ, Saklofske DH, Huang SHS, McKenney D. Measurement of trait emotional intelligence: testing and cross-validating a modified version of Schutte et al.'s (1998) measure. Personality and Individual Differences. 2004; 36(3):555-62.

23. Pulakos ED, Arad S, Donovan MA, Plamondon KE. Adaptability in the workplace: development of a taxonomy of adaptive performance. J Appl Psychol. 2000;85(4):612-24.

24. Schutte NS, Malouff JM, Hall LE, Haggerty DJ, Cooper JT, Golden CJ, et al. Development and validation of a measure of emotional intelligence. Personality and Individual Differences. 1998;25:167-177.

25. Malec JF, Kragness M, Evans RW, Finlay KL, Kent A, Lezak M. Further psychometric evaluation and revision of the Mayo-Portland Adaptability Inventory in a national sample. Journal of Head Trauma Rehabilitation.2003;18 (6):479-492.

26. Grant AM, Ashford SJ. The dynamics of proactivity at work. Research in Organizational Behavior. 2008;28: 3-34.

27. Dunphy B, Williamson S. In pursuit of expertise. Toward an educational model for expertise development. Adv Health Sci Educ Theory Pract. 2004;9:107-127.

28. Fitts PM, Posner MI. Human performance. Belmont, CA: Brooks Cole; 1967.

29. Lave J, Wenger E. Situated learning: legitimate peripheral participation. Cambridge, UK: Cambridge University Press; 1990. 